\title{
Studies of Wushu Specialized Course Teaching Reform of Physical Education Specialty in Ordinary Universities
}

\author{
Weihua Liu \\ College of Physical Science, Jishou University, Hunan Jishou 416000, China \\ xxhw1916@aliyun.com
}

\begin{abstract}
Keywords: Ordinary universities; Physical education specialty; Wushu specialized course; Teaching reform
\end{abstract}

\begin{abstract}
Wushu specialized course teaching of physical education specialty in ordinary universities should adhere to education-oriented teaching concept at the core of cultivating students' Wushu education practice quality, implements the "seminar-style teaching" classroom teaching model, strengthen the innovativeness and practicalness of Wushu, and construct the "open and inclusive" practical teaching innovation model of Wushu specialized course teaching of physical education specialty in ordinary universities, so as to cultivate and transport "high-quality, high-attainment, high-level and diversified" Wushu education talents for schools at all levels of different varieties.

A high-quality teacher team is the foundation for China's education career development, as well as the key to comprehensively improve education quality of education. For further deepening the teacher education reform, comprehensively improving teaching training quality, and establishing a high-quality professional teaching team, the Ministry of Education promulgated the "Teacher Education Course Standard (Trial)" (hereinafter referred to as the "Course Standard") in October 2011, set up standards of teacher education course standard for educational institutions and provided guidlenline instructions for cultivating high-quality professional teachers' team. ${ }^{[1]}$
\end{abstract}

Wushu specialized course teaching of physical education specialty in ordinary universities (hereinafter referred to as Wushu specialized course) with cultivating martial arts teachers at all levels in all types of schools as the principal shoulders the heavy responsibility of cultivating "high-quality, high-quality self-cultivation, high-level, and diversified" Wushu teachers. According to the current status of classroom teaching of Wushu specialized course, most teachers use the traditional"oral instruction and physical demonstration, namely, action explanation $\rightarrow$ demonstration $\rightarrow$ students' imitation and practice $\rightarrow$ teacher's correction $\rightarrow$ students' self-learning $\rightarrow$ summary. Students can gradually master the essentials of movements until they fully obtain skills after teachers repeatedly explain action, demonstrate, and corrects mistakes. Although this traditional teaching method can directly help students to acquire Wushu skills through repeated imitations and practice, the teaching behavior under the limitation of teachers' unilateral education makes students confined to intuitive perception and cognition of the action appearances. This will easily make students think that the "learning-practice" of Wushu movements means the comprehensive cognition of Wushu technique, and it is impossible for them to experience the profoundness and cultural connotation of the Chinese martial arts during the learning process. At the same time, the teaching evaluation of this teaching model will only focus on how many students master martial arts skills, how good or bad they have learned and the level of individual student's martial arts skills, meanwhile will overlook students' subjective initiative and creativity in the learning process. It can be seen that if "oral instruction and physical demonstration" used as the only method of Wushu specialized course will make the course teaching dominated by teaching Wushu techniques, which makes schools unable to truly inherit and carry forward Chinese excellent traditional culture, or completely, accurately and effectively achieve the cultivation goal of Wushu specialty of physical education in ordinary universities.

Therefore, Wushu specialized course teaching of physical education specialty in ordinary universities should follow Teacher Education Course Standard, adhere to education-oriented teaching concept at the core of cultivating and transport "high-quality, high-attainment, high-level and diversified" Wushu education talents, implements the "seminar-style teaching" classroom teaching 
model, strengthen the innovativeness and practicalness of Wushu, and spare efforts to improve students' comprehensive attainment, construct the "open and inclusive" practical teaching innovation model.

\section{Constantly Maintain students' Dominant Role in Classroom Teaching}

Wushu specialized course teaching should not only focus on cultivating students' Wushu skills, but also needs to highlight the professional characteristics of Wushu major students in "one specialization and all-round capabilities" based on Wushu education practice ability, and cultivate a group of high-quality Wushu education workers with solid professional knowledge, perfect mastery of ideology, strong sense of social responsibility, innovative spirit, practical ability and profound moral qualities. In accordance with the spirit of the "Course Standard," Wushu specialized course teaching should focus on students' interest in learning, enriching students' cognition of Wushu and stimulating students' enthusiasm for learning by making use of course resources. It should concentrate on students' requirements, guide students to take emotional experience as the guide, think actively, express freely, and practice diligently, interact with teachers, and always maintain the student's dominant role in classroom teaching. Meanwhile it is necessary to know each student's learning dynamics and effects, make full use of the practice in the course, conduct teaching practice activities by guiding students' multi-channel and multi-level utilization of knowledge and encourage students to freely imagine and innovate boldly in the process of practice, and maximally stimulate students' imagination and creativity of Wushu technical movements, so that students can feel and enjoy the fun during the process of creation , thus promoting healthy development of students' personality and the individual's comprehensive development.

\section{Implement "seminar-style Teaching" Classroom Teaching Model}

"Seminar-style teaching" is a problem-solving centered teaching method in which teachers set up problem situations, then teachers and students work together to find out information, research, discuss, practice, explore, and propose ways to solve problems so that students can acquire knowledge and skills. $^{[2]}$

Implementation Process. During implementing "seminar-style teaching", it is necessary to arrange discussion contents which can stimulate students' learning interest according to the teaching plan, content, and purpose of the Wushu specialized course; secondly, follow the principle of combining teacher distribution and independent choice when arranging discussion groups, and strive to achieve a balanced distribution of professionalism and competency in each discussion group; next, teachers should arrange the topics for discussion in advance according the teaching progress, and guide students to put classroom knowledge into real life. Teachers should teach them to apply what they have learned, but also teach students to know why and how to use it. Finally, after the students complete the main content of the discussion, teachers should organize students to carry out exchanges and discussions within the group, and select representatives to express group views in the class, answer questions from teachers and their groups. Through the communication, students can improve their language expression ability, summary ability and on-spot reaction. After the end of discussion, teacher should summarize the contents of discussion, supplement and guide students to think further, and broaden the breadth

and depth of their knowledge.

Effect Analysis. Teaching methods can only achieve good results when they meet the objective rules of the teaching process and adapt to the students' learning psychology and learning ability ${ }^{[1]}$. Through the empirical study of the seminar-style teaching method in Wushu specialized course, a questionnaire survey of student satisfaction was conducted with relevant teaching effects obtained.

1) Reflect students' dominant role and improve students' learning interest. The seminar-style teaching method has realized the individuation of knowledge learning in Wushu specialized course which makes the learning space more open and relaxed, the learning atmosphere more lively and fully mobilizes students' enthusiasm for learning so that they have changed from passive to be initiative in 
teaching activities, which reflects the student's dominant role; it makes the teacher-student interaction more convenient, thus greatly stimulating students' curiosity and learning interest, broadening their thinking and horizon, enriching the students' theoretical knowledge, and achieving extremely high students' satisfaction for classroom teaching.

2) comprehensive quality is improved.It requires students to conduct literature searching and information processing before conducting the thematic discussion. During the discussion, students of different majors should communicate with each other, express their own viewpoints, summarize group's opinions when making speeches as the group representative, and answer questions, which can greatly practice students' ability to find problems, analyze problems, solve problems and express themselves verbally, and can cultivate the students' spirit of independent thinking and labor division, labor, and greatly help students' to develop scientific thinking mode.

3) Teacher-student communication can be strengthened.Before confirming the discussion and during the seminar, students should exchange questions and answers with teachers, which can increase teacher-student exchanges, and promote teacher-student relationships; it can also promote mutual learning, communication, mutual understanding for students from different backgrounds and regions during group discussions, and can create a good and active classroom atmosphere.

4)It can promote to develop students' Wushu techniques and improve students' Wushu movements.Students can understand the essentials, composition, rhythm, and methods of Wushu movements in advance from pre-class seminar discussion tasks. It can help students to develop correct Wushu movement pattern and improve students' mastery of Wushu skills combined with the teacher's explanations and demonstrations in classes based on students' reflections after class. Through the seminar-type teaching method, students' thinking ability, practical operation ability and language expression ability can be cultivated. At the same time, students' solidarity and cooperation spirit can be fostered by guiding the division of labor among students. It then guides students to think positively and create boldly so that students can transform passive learning into interesting and creative practical processes, thus stimulating students' sense of innovation and practical ability. Also, it can promote them to actively seek out ways to solve problems in the course of repeated practice, Students' ability to coordinate, communicate and collaborate, and the ability to identify problems and solve problems through teamwork can be enhanced during the process of achieving learning goal.

In view of the current Wushu specialized course classroom teaching, it is mostly conducted by one teacher to several students in a collective teaching manner. This type of classroom teaching which can usually meet the general needs of most students but cannot meet the individual needs of each student. Therefore, Wushu specialized course classroom teaching should be conducted based on students' commonality and individual differences of each student by setting up individualized learning goals, and transforming the oral teaching mode of the classroom teaching into a seminar-style teaching mode with individual development as the goal, which can help students to gain personal skills in the "seminar" classroom atmosphere.

In Wushu specialized course teaching, teachers should make full use of students' initiative and enthusiasm in completing learning objectives, encourage students to freely choose partners, select action contents, choose expressions, and cooperate with each other to achieve mutual success, develop the motivation change into a creative process with theme and image until the completion of a new Wushu work (including self-selected pattern, Wushu exercise, Wushu programs). The practical process of this kind of creation is the process of "seminar" between teachers and students, students and students. In the "seminar" process, students can not only obtain the experience of Wushu creation, but also can improve their Wushu arrangement and guidance capabilities, meanwhile cultivated cooperation consciousness, expression ability and problem-solving skills.

The classroom teaching model from passive learning to initiative learning can fully mobilize students' learning activity and get each student to actively precipitate into classroom teaching so that the classroom is full of vitality and interest. 


\section{Establish an Open and Inclusive New Practical Course Model}

It has been clearly required in "Course Standard" that "teacher education course should guide future teachers to establish a correct concept of children, students, teachers and education, master the necessary educational knowledge and ability, participate in educational practice, cultivate social responsibility, innovative spirit and practical ability." "Teacher education course should strengthen practical awareness, focus on practical issues, and reflect new requirements for teachers in education reform and development. Teacher education course should guide future teacher to participate and research basic education reform, take initiative to construct educational knowledge and develop practical ability." ${ }^{[3]}$ Therefore, in Wushu specialized course teaching, it is necessary to continuously adjust the course structure to help students acquire practical experience and experience and improve students' educational practice ability. Educational practice ability is the capability based on the actual situation of the teaching scene by which teachers can quickly analyze and judge and quickly and professionally select appropriate educational methods and methods to organize and carry out teaching activities. With practical knowledge as the core, it includes basic qualities of education, students' comprehensive qualities such as personality and quality, learning ability, and exploration ability, as the professional foundation for individual teacher's sustainable development. It requires to change educational concepts and innovate curriculum teaching model in Wushu specialized course teaching, but also requires to further improve the curriculum education practice system, strive to build a new model of "open and inclusive" practical courses, guide students to conduct Wushu practice through practical activities, and obtain professional foundation for sustainable development, and acquire professional qualifications and educational practice ability for Wushu teachers.

Emphasize to Cultivate Students' Education Research Awareness. It is clearly stipulated in "Course Standard" that the "teacher education course" should "guide the future teachers to discover and solve practical problems, achieve professional development in the process of researching their own experiences and improving education and teaching behavior, and form personal teaching style and practical wisdom" ${ }^{[3]}$. Therefore, cultivating students' educational research consciousness is the primary task of the teacher education course. Wushu specialized course teaching should try to create space for students to learn independently, based on classroom or extra-curricular activities such as "New Year's Day Gala", "Graduation Party", "New Year Party", "Education Practice", and "Subject Contest", help students to think and create, guide students to design from Wushu action modeling to Wushu pattern and exercise, compile Wushu action combination to Wushu program, from music selection to clothes matching, from creative conception to performance of Wushu works, encourage students to boldly apply Wushu comprehensive skills that they have learned for Wushu creation practice activities, guide students to actively seek the rules and aesthetics of Wushu movement changes, and actively study creative Wushu arts pattern and Wushu program in the process of creation practice so that students have confidence and interest in Wushu creation activities. Meanwhile, it can also cultivate students' ability to find problems, analyze problems and solve problems, and gain experience of Wushu education practice skills, basic ability to study Wushu education during the process of various activities and actively reflecting results.

Cultivate Students' Wushu Qualities.Course teaching as a cooperative process for teachers and students to explore together emphasizes the individual experience of students in the learning process, in which course content is an integral component. In the course teaching, teachers need to continuously adjust their own teaching thinking and methods based on specific conditions in the teaching process, pay attention to the new goals and tasks produced during the course of teaching, and jointly explore and achieve the course goals together with the students.

Wushu specialized course teaching should be conducted bon the actual situation of the students and course teaching needs. It is necessary to set up some dynamic course links that are conducive to improving the students' ability in the teaching process, adjust the content and methods of the teaching at any time to meet new goals and actual students' needs in the teaching process so that "exploration" can be conducted throughout the entire course. During the teaching process of Wushu skill courses, students are encouraged to actively study and actively explore, timely adjust teaching content and 
methods according to errors in the spatial position and orientation errors of students in the process of completing Wushu skills, guide students to compare the aesthetic expressions of the movements in different positions and orientations of the space through action comparison between individuals, group-individual and groups so that students can actively explore how to make the spatial action more aesthetic in spatial position, how to make actions with beauty-appreciation in the orientation point, and how to make the formation scheduling more reasonable, ultimately to make the classroom full of "exploration" meaning, combine course practice organically with the cultivation of students' innovation awareness and inquiry quality, and make course teaching into an important means of cultivating students to explore Wushu quality.

Pay Attention to Students' Wushu Innovation Awareness.It is clearly stipulated in "Course Standard" that the core of the teacher education course reform is to improve teaching methods and teaching means. In the course of teaching, it is necessary to spare efforts improving students' practical ability and innovation ability. Therefore, the Wushu specialized course teaching should integrate course with extracurricular activities according to specialty characteristics, encourage students to actively participate in Wushu creation practice creation, and guide students in actively exploring various ways to accomplish creative practice in the process of practice. Various problems that arise in the practice of writing. For example, relying on the Basic Skills Contest for Sports Education, Graduation Party, Welcome Party, and University Student Literature and Art Exhibition and various social and literary practice activities to guide students to apply the martial arts skills acquired in course teaching to their bold applications. Martial arts creation practice, and in the process of practice, encourage students to be creative, constantly explore new ideas and methods of martial arts creation, innovatively solve various problems encountered in the practice of creativity, make creative practice full of innovation and vitality, and make creative practical process become a practical process of innovation, and a way for students to acquire martial arts innovation and comprehensive ability.

Establish Mutual-assisting and Equal Teacher-student Relationship.Course teaching is not a unilateral teaching process for teachers. Instead, teachers and students explore together to reach a consensus in the process of mutual respect, mutual influence, and common exploration of related topics. This process includes teacher-student mutual understanding, mutual influence, and joint efforts. Teachers who are no longer the absolute authority in course teaching, become are the guide for activities, and develop positive emotions in the joint exploration of teachers and students, gain achievements and satisfaction, and obtain professional and professional development. Through the interaction between teachers and students, students become participants and active learners, and establish mutual assistance and equal teacher-student relationship in the process of exploring with teachers so that Wushu specialized course teaching is no longer just to complete the preset goal plan. Instead, it pays more attention to the new goals and new tasks during the course learning.

Wushu specialized course teaching is an important way to cultivate the professional ability and professional quality of future Wushu educators. Therefore, in the course teaching, teachers should be good at creating an on-spot teaching environment full of change. Through setting up questions and inquiry teaching links, teachers should strive to give full play to the initiative and enthusiasm of students in mutual and equal teacher-student relations, guide students to actively explore various ways to solve problems, encourage students to actively explore with teachers and master Wushu skills and innovation skills required for professional development in the future, and upgrade Wushu education and teaching qualities of students to finally achieve their individual personality development.

Realize Mutual Integration of Classroom Teaching and Information-based Teaching. With the constant popularization and development of the Internet, the Internet has become an important part of people's life. Open and diversified Internet breaks the traditional space-time concept, provides a new platform for people to obtain new information and communicate, and also provides new contents and new ways for teacher education course system.

Establishing Wushu specialized course network teaching platform by using Internet information technology can effectively extend the classroom teaching to the network, so that students can immediately absorb and use the teaching resources on the Internet and realize the deep integration of 
classroom teaching and online learning. In this way, students' learning approaches can be broadened, so that students can acquire the most advanced Wushu knowledge and skills at any time. Students' learning will be more autonomous and personalized. Teachers also have more time to guide and expand students' skills. Due to its own particularity, teachers face many difficulties in teaching. For example, in teaching, teacher's instruction should focus on students' commonality of students, but also should develop students' individuality of the students. A teacher usually has to face more than a dozen or dozens of students in class, and should take care of classroom safety while ensuring to develop individual differences, interests, characteristics, and specialty of each student, which makes it very difficult to carry out courses. And network information technology can solve these problems.

Wushu specialized course teaching integrating information technology can help students download, study, communicate, explore and research classroom learning and research tasks in a timely and fast manner, upload their own martial arts works or self-media works to the internet for teachers to timely know and control students' learning, adjust classroom teaching content and progress, and provide teachers and students with a space for extracurricular answering, exchange, discussion and exploration. This can build a platform for interaction between teachers and students that transcends space and time, provide channels for communication between students, teachers and peers. This can greatly stimulate the enthusiasm of independent learning, Wushu innovation ability and personality development through mutual cooperation and exchange and then students can get beneficial growth in the cyberspace.

Further Perfect Course Evaluation Concept. Traditional Wushu specialized course evaluation adopts student's Wushu professional skill level as the main evaluation index, lacks the evaluation index with humanistic care for the students' own value and comprehensive development as the core. With the continuous deepening of college curriculum reform, we are increasingly aware that Wushu education is not only a professional education, but also a cultivation of students' humanistic feelings. Therefore, Wushu specialized course teaching for physical education major should not only pay attention to the development of students' professional Wushu skills, but also should pay attention to the overall development of students. It is necessary to focus on cultivating students' morality, core values, martial arts aesthetic qualities and humanistic qualities, focusing on cultivating students' Wushu innovation abilities, focusing on improving students' comprehensive qualities, promoting the overall development of students' Wushu quality, and laying foundation for them to develop life-long love, enjoyment for Wushu, Wushu creation and sustainable development.

Therefore, in the course evaluation, we will focus on promoting students' overall development in the future. We will include students' morality, core values, Wushu aesthetic qualities, humanistic qualities, Wushu comprehensive accomplishment, Wushu innovation ability, and teamwork ability into the evaluation system, set Wushu systemic system theory and future teaching skills of Wushu teachers as an important part of course evaluation; set basic theory of Wushu-related philosophy, literature, aesthetics, and education disciplines and Wushu skill level testing, Wushu creation practice and martial arts teaching Practical skills, martial arts research ability, and the ability to organize and develop and participate in all levels of Wushu competitions and Wushu activities as the specific content of the course evaluation, in line with the students' education practice, Wushu practice activities and effective teachers in the activities, and make comprehensive evaluation of students' Wushu education quality and Wushu comprehensive quality.

The multi-channel and multi-angle evaluation method can truly examine the students' Wushu comprehensive ability, and identify problems, solve problems and martial arts innovation abilities during the practice of martial arts, so that the evaluation can become an important means for every student to fully perform, freely express and comprehensive develop their personalities. In this evaluation process, it has highlighted the enhancement of students' Wushu comprehensive literacy, and meanwhile focuses on the educational experience of students; it has concerned about the improvement of teachers' professional ability, and meanwhile care for the improvement of teachers' professional value. It has truly achieved the goals of course teaching for the individualized and comprehensive development of students and teachers, and realized the new concept of course evaluation focusing on the common development of students and teachers. 


\section{Conclusion}

Wushu specialized course teaching of physical education specialty in ordinary universities should adhere to education-oriented teaching concept at the core of cultivating students' Wushu education practice quality, cultivate a group of high-quality Wushu education workers with solid professional knowledge, perfect mastery of ideology, strong sense of social responsibility, innovative spirit, practical ability and profound moral qualities. In course teaching, it is necessary to highlight the professional characteristics of Wushu major students in "one specialization and all-round capabilities" based on Wushu education practice ability, at the core of cultivating students' Wushu education practical quality, implements the "seminar-style teaching" classroom teaching model, strengthen the innovativeness and practicalness of Wushu, and construct the "open and inclusive" practical teaching innovation model of Wushu specialized course teaching of physical education specialty in ordinary universities, so that course teaching can serve to cultivate and transport "high-quality, high-attainment, high-level and diversified" Wushu education talents for schools at all levels of different varieties.

\section{Acknowledgements}

2018 Hunan Provincial Social science achievement appraisal committee project (XSP18YBC151)

\section{References}

[1] Liao Ping. Exploration of dance major course teaching reform in normal colleges [J]. Journal of Beijing Dance Academy, 2017, (4):65-69.

[2] Liu Weihua. Practical application of seminar-style teaching in college public physical education - take taekwondo elective course as the example [J]. Contemporary Sports Technology, 2017, (36):77-78.

[3] Opinions of Ministry of Education on vigorously promoting teacher education curriculum reform[EB/OL] [2011-10-08] http://www.moe.gov.cn/srcsite/A10/s6991/201110/t20111008_ 145604.html

[4] Yu D, Peng L. When does Inferring Reputation Probability Countervail Temptation in Cooperative Behaviors for the Prisoners' Dilemma Game? [J]. Chaos, Solitons \& Fractals, 2015, 78: 238-244. 